\title{
Accumulation of phytoene and astaxanthin and related genes expression in Haematococcus pluvialis under sodium acetate stress
}

\author{
Xiaomei Cong, Xiaonan Zang*, Manman Dong, Zhendong Wang, Bangxiang He, \\ Lulu Hou, Xuehong Wei, Feng Zhang, Menghui Shang, Zhaxi Yangzong, Rui Li, \\ Xuecheng Zhang
}

Key Laboratory of Marine Genetics and Breeding (Ocean University of China), Ministry of Education, Qingdao 266003, Shandong, PR China

\begin{abstract}
Phytoene and astaxanthin are 2 important carotenoids in the green alga Haematococcus pluvialis. Under environmental stress, the synthesis of phytoene in $H$. pluvialis increases significantly, and phytoene is converted to astaxanthin through enzymatic catalysis. This paper analyzes the relationship between astaxanthin and phytoene accumulation in carotenoid synthesis pathways under different concentrations of sodium acetate $(\mathrm{NaAc})$ by high-performance liquid chromatography. The highest concentrations of phytoene and astaxanthin were observed at the NaAc concentration of $6 \mathrm{~g} \mathrm{l}^{-1}$ on the $12^{\text {th }}$ day of induction. The highest astaxanthin concentration achieved was $2.26 \pm 0.28 \%$. Therefore, we concluded that $6 \mathrm{~g} \mathrm{l}^{-1} \mathrm{NaAc}$ and induction for $12 \mathrm{~d}$ provided the optimal inducing conditions for astaxanthin accumulation in $H$. pluvialis. psy, pds, lcyB, $\beta$-carotene ketolase $c r t w$, and $c r t z$, which are genes related to phytoene and astaxanthin synthesis, were cloned and studied at the transcriptional level. crtw and crtz were continuously up-regulated since the first day of induction, while $p s y$, $p d s$, and $l c y B$ were continuously up-regulated starting on the $3^{\text {rd }}$ day of induction. These findings are important for enhancing our understanding of the mechanism of accumulation of phytoene and astaxanthin in $H$. pluvialis and provide a foundation for identifying the induction conditions necessary for optimizing astaxanthin production and increasing astaxanthin yields.
\end{abstract}

KEY WORDS: Haematococcus pluvialis - Sodium acetate - Phytoene ' Astaxanthin . Gene transcription $\cdot$ Induction conditions $\cdot$ HPLC $\cdot$ Astaxanthin-phytoene relationship

\section{INTRODUCTION}

Astaxanthin is a red carotenoid pigment with a high commercial value that has attracted considerable attention for its biological properties, such as its antioxidant, anti-inflammatory, and anti-cancer activities, as well as its coloring for fish (Fujii 2015). Green microalgae are the main natural source of astaxanthin, and also provide ideal models for studying the regulation of ketocarotenoid synthesis (Linden 1999, Grünewald et al. 2001). The unicellular green

\footnotetext{
${ }^{*}$ Corresponding author: xnzang@ouc.edu.cn
}

alga Haematococcus pluvialis is mass cultivated and produced at an industrial scale (Liu et al. 2014). The life cycle of $H$. pluvialis is divided into 2 stages: the green stage and the immobile stage (Boussiba 2000). Astaxanthin is accumulated during the process of transformation from the green motile vegetative cells to the aplanospore stage (Fábregas et al. 2000). Additional work is needed to enhance our understanding of astaxanthin biosynthesis, the accumulation and degradation of carotenoids, and the role of the expression of carotenogenic genes in these processes.

() The authors 2020. Open Access under Creative Commons by Attribution Licence. Use, distribution and reproduction are unrestricted. Authors and original publication must be credited. 
In autotrophic plants and bacteria, carotenoids are important components of photosynthetic membranes and can absorb and transmit light energy. Therefore, when the synthesis of these carotenoids is inhibited, the photosynthesis and growth of plants do not proceed at normal rates (Jackson et al. 2008, Poojary et al. 2016). Carotenoids can be produced during the growth and metabolism of $H$. pluvialis. Phytoene is an important carotenoid precursor of astaxanthin (Harker \& Young 1995), as it is the first carotenoid produced during astaxanthin synthesis. Moreover, the accumulation of phytoene is closely tied to astaxanthin production. Here, we study the relationship between astaxanthin and phytoene under induction conditions to enhance our understanding of the accumulation process of astaxanthin and identify the most optimal induction conditions for astaxanthin synthesis.

Phytoene synthase (PSY) and phytoene desaturase (PDS) are the first 2 enzymes that play fundamental roles in the carotenoid biosynthetic pathway. Phytoene is synthesized from 2 geranylgeranyl diphosphate molecules under the action of PSY, followed by the conversion of phytoene into $\zeta$-carotene by PDS. The formation of $\beta$-carotene from lycopene is catalyzed by lycopene cyclase. Astaxanthin biosynthesis follows a general carotenoid biosynthesis pathway up to $\beta$-carotene, and astaxanthin is produced with $\beta$ carotene as precursor by the action of $\beta$-carotene ketolase (CRTW) and $\beta$-carotene hydroxylase (CRTZ) (Lotan \& Hirschberg 1995, Fraser et al. 1998). Sodium acetate (NaAc) might stimulate the accumulation of astaxanthin in H. pluvialis (Raman \& Ravi 2011). Gao et al. (2012) analyzed the transcriptional expression of ipi-1, psy, pds, crtR-B, lyc, ipi-2, bkt, and crtO from $H$. pluvialis inducted by $\mathrm{NaAc}$ in the absence of other stimuli. Given that NaAc is an important inducer of astaxanthin synthesis, we focus on its effects on the transcriptional levels of 5 key genes involved in astaxanthin synthesis - crtw, crtz, psy, $p d s$, and $l c y B$ - to provide a foundation for furthering our understanding of the mechanisms underlying astaxanthin synthesis.

This study uses NaAc as the carbon source to induce red cysts and compares the accumulation of phytoene and astaxanthin under different concentrations of NaAc by high-performance liquid chromatography (HPLC). The transcriptional expression of carotenogenic genes during astaxanthin biosynthesis was analyzed using qRT-PCR. This research will provide a foundation for deepening our understanding of astaxanthin accumulation in $H$. pluvialis and its optimal induction conditions.

\section{MATERIALS AND METHODS}

\subsection{Algal culture, growth conditions, and NaAc induction}

Haematococcus pluvialis was obtained from the Laboratory of Phycology at the Ocean University of China. The cells were grown in Bold's Basal Medium (BBM; Tripathi et al. 1999) (per liter: $0.3 \mathrm{~g}$ $\mathrm{NaNO}_{3}, 0.0851 \mathrm{~g} \mathrm{~K} \mathrm{HPO}_{4} \cdot 3 \mathrm{H}_{2} \mathrm{O}, 0.1521 \mathrm{~g} \mathrm{KH}_{2} \mathrm{PO}_{4}$, $1 \mathrm{~g} \mathrm{NaAc} \cdot 3 \mathrm{H}_{2} \mathrm{O}, 0.074 \mathrm{~g} \mathrm{MgSO}_{4} \cdot 7 \mathrm{H}_{2} \mathrm{O}, 0.0189 \mathrm{~g}$ $\mathrm{CaCl}_{2}, 0.0561 \mathrm{~g} \mathrm{KOH}, 7.6 \mathrm{mg}$ ferric citrate, $0.05 \mathrm{mg}$ $\mathrm{VB}_{12}, 10 \mathrm{mg}$ EDTA, and $1 \mathrm{ml} \mathrm{A5+Co} \mathrm{solution).} \mathrm{The}$ illumination was $50 \mu \mathrm{mol}$ photons $\mathrm{m}^{-2} \mathrm{~s}^{-1}$ during the growth phase and $172 \mu \mathrm{mol}$ photons $\mathrm{m}^{-2} \mathrm{~s}^{-1}$ during the induction phase. The cells were cultured with a 12:12 h dark:light cycle at $23 \pm 1^{\circ} \mathrm{C}$ without aeration and shaken 3 to 5 times daily. When the cell concentration reached $(4-5) \times 10^{5}$ cells $\mathrm{ml}^{-1}$, they were transferred to an induction culture (He et al. 2018), which contained $100 \mu \mathrm{FeSO}_{4} \cdot 7 \mathrm{H}_{2} \mathrm{O}\left(0.05 \mathrm{mg} \mathrm{l}^{-1}\right)$, $100 \mu \mathrm{VB}_{12}\left(0.05 \mathrm{mg} \mathrm{l}^{-1}\right)$, and $100 \mathrm{ml} \mathrm{NaAc}$ (at concentration gradients of $0,3,4,5$, and $6 \mathrm{~g} \mathrm{l}^{-1}$ ). All of the treatments were conducted in triplicates of $250 \mathrm{ml}$. Light intensity was changed from 50 to $172 \mu \mathrm{mol}$ photons $\mathrm{m}^{-2} \mathrm{~s}^{-1}$.

\subsection{Determination of phytoene and astaxanthin}

\subsubsection{Extraction of carotenoids}

Carotenoids were extracted by acetone (Dere et al. 1998). After induction, $100 \mathrm{ml}$ of algal cells were harvested by centrifugation and stored at $-80^{\circ} \mathrm{C}$ for 2-3 h. Next, the algal sludge was freeze-dried and weighed, and the powder was poured into a $10 \mathrm{ml}$ centrifuge tube. Three $\mathrm{ml}$ of acetone was added and ultrasonically extracted for $15 \mathrm{~min}$ on ice, followed by centrifugation. The supernatant was then transferred to a $5 \mathrm{ml}$ volumetric with the addition of up to $5 \mathrm{ml}$ of acetate. The solution was filtered through a $0.22 \mu \mathrm{m}$ filter membrane as samples were tested.

\subsubsection{HPLC analysis of phytoene and astaxanthin}

Agilent Technologies 1260 Infinity Omnipotent gel filtration chromatograph, 1260 Infinity Quaternary pump, TCC Column Compartment, and LC Solution (Agilent Technologies) was used to determine phytoene and astaxanthin in $H$. pluvialis. The 
analytical conditions were: Amethyst $\mathrm{C}_{18}-\mathrm{H}$ column $(250 \mathrm{~mm} \times 4.6 \mathrm{~mm}, 5.0 \mu \mathrm{m})$, flow rate $=1 \mathrm{ml} \mathrm{min}^{-1}$, detection: $287 \mathrm{~nm}$. Mobile phase was methanol:THF (75:25), and the column temperature was $30^{\circ} \mathrm{C}$. The sample size was $20 \mu \mathrm{l}$.

\subsubsection{Preparation of standard curve}

Phytoene and astaxanthin standards were purchased from MD Bio (MD Biosciences). Phytoene and astaxanthin were dissolved by acetone to make the final concentrations either 2, 4, 6, 8, or $10 \mathrm{\mu g} \mathrm{m}^{-1}$. Five different concentrations of standards $(20 \mu \mathrm{l})$ were injected into the HPLC, and the linear regression equation for the standard curve was obtained by plotting the amount of the standard compound injected against the peak area.

\subsection{RNA isolation and cDNA synthesization}

Algal samples with different concentrations of $\mathrm{NaAc}$ were harvested by centrifugation and ground into a fine powder using a mortar and pestle. Total RNA was then extracted using Plant RNA Kit (Omega Bio-Tek). Genome DNA was digested by RNase-Free DNase I Set (Omega Bio-Tek). The cDNA was prepared by using PrimeScript ${ }^{\mathrm{TM}} \mathrm{RT}$ reagent Kit (TaKaRa).

\section{4. qRT-PCR analysis}

The primers used for amplification of $c r t z, c r t w$, $p s y, p d s$, and $l_{c y} B$ were all synthesized (Sangon) (Table 1) according to the sequences obtained from

Table 1. Gene-specific primers used for qRT-PCR. -F: forward; -R: reverse

\begin{tabular}{|llc|}
\hline Primer & Primer sequence $\left(5^{\prime}-3^{\prime}\right)$ & Temperature $\left({ }^{\circ} \mathrm{C}\right)$ \\
\hline CRTZ-F & ATC TTC GCC ACC TAC CTG AG & 52.5 \\
CRTZ-R & CGG GCA GTC CAT TGA TGA TT & 50.4 \\
CRTW-F & GGA GCA CCA CAA CCA TAC TG & 52.5 \\
CRTW-R & CGA AGT AGA AGA GGC GGA ATG & 52.8 \\
PSY-F & GTC GAC GGT CCA AAC GCC AAT AA & 55.2 \\
PSY-R & GTC TGG TAT CGA GTC TTA TGC AAA TCC & 55.9 \\
PDS-F & TTT CTC GCT TTG ACT TCC CT & 48.4 \\
PDS-R & ACA CTT CCT CAT TGA CTC GG & 50.4 \\
LCYB-F & AAC AAC GCC CTG CCT ACC TT & 52.5 \\
LCYB-R & TCC TCC ACT GCC TTG ACC TT & 52.5 \\
rbcL-F & ACG AAT GTT TAC GCG GTG GTC T & 53.1 \\
rbcL-R & GGT ACA CCC AAC TCC TTA GCA & 52.8 \\
\hline
\end{tabular}

the transcriptome library constructed in our laboratory. The large subunit of ribulose 1,5-diphosphate carboxylase/oxygenase gene was used as the internal standard. PCR products were then quantified continuously with the BIOER LineGene 9640 (Bioer Technology) using TB Green Premix Ex Taq II (TaKaRa) according to the manufacturer's instructions. The PCR amplification profile was $95^{\circ} \mathrm{C}$ for $10 \mathrm{~min}$ followed by 40 cycles of $95^{\circ} \mathrm{C}$ for $15 \mathrm{~s}$, and $53^{\circ} \mathrm{C}$ for $60 \mathrm{~s}$. The $2^{-\triangle \Delta \mathrm{Ct}}$ method was used to analyze the transcript abundance of relative gene expressions (Livak \& Schmittgen 2001).

\subsection{Statistical analysis}

Graphing and statistical analysis were performed using Origin 8.5 (OriginLab). Student $t$-tests were used for comparing the cell dry weight of $H$. pluvialis and the accumulation of astaxanthin and phytoene, under different concentration of NaAc and over time. Pearson correlation analysis was done to evaluate the correlation between accumulation of astaxanthin and phytoene. A p-value of $<0.05$ was considered to be significant.

\section{RESULTS}

\subsection{Determination of standard curve of phytoene and astaxanthin by HPLC}

\subsubsection{Effect of NaAc concentration on dry weight} accumulation of Haematococcus pluvialis

During the induction of Haematococcus pluvialis, the dry weight of the cells in the different concentration groups of NaAc increased to varying degrees (Fig. 1). Medium concentrations $\left(4-5 \mathrm{~g} \mathrm{l}^{-1}\right)$ of NaAc in the early stage $\left(0^{\text {th }}-4^{\text {th }}\right.$ day $)$ increased the weight of the algal cells significantly ( $p<0.05$ ), and high concentrations $\left(6 \mathrm{~g} \mathrm{l}^{-1}\right)$ of $\mathrm{NaAc}$ reduced the dry weight of the algae slightly from 0.138 to $0.136 \mathrm{~g} \mathrm{l}^{-1}$. From the $8^{\text {th }}$ to the $12^{\text {th }}$ day, $3-6 \mathrm{~g} \mathrm{l}^{-1}$ concentrations of $\mathrm{NaAc}$ all began to promote a steady increase in cell dry weight. On the $16^{\text {th }}$ day, the 4 groups at different $\mathrm{NaAc}$ concentrations had similar dry weights, which were much higher than that of the group without NaAc $(p<0.05)$. 


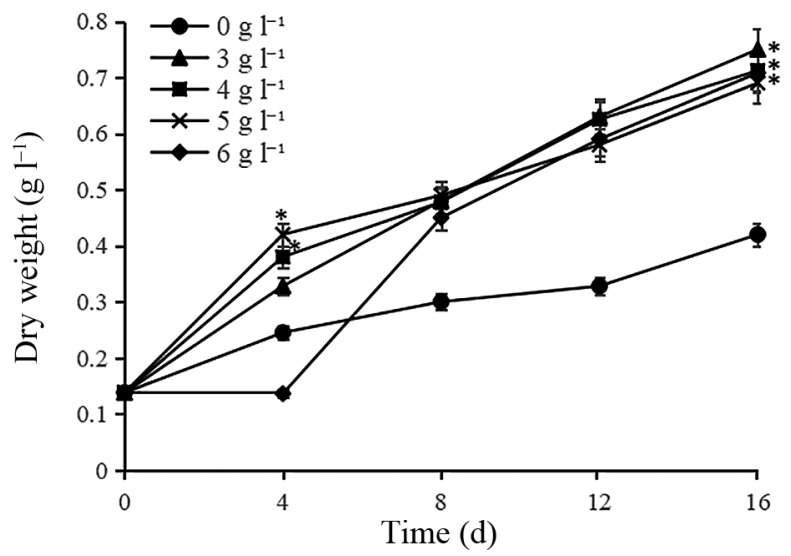

Fig. 1. Effect on cell dry weight of Haematococcus pluvialis of different concentrations of sodium acetate. All data show mean \pm SD. Three independent experiments conducted $(\mathrm{n}=3) .{ }^{*} \mathrm{p}<0.05$

\subsubsection{Standard curve of phytoene and astaxanthin}

Standard phytoene and astaxanthin were detected by HPLC (Fig. 2). Since the phytoene standard purchased contains $30 \%$ cis-phytoene, there were 2 peaks. The first peak corresponded to trans-phytoene and the second peak to cis-phytoene. The peak times of trans- and cis-phytoene were 13.216 and $13.598 \mathrm{~min}$, respectively. The peak time of the astaxanthin standard was $9.584 \mathrm{~min}$.

The standard solutions of the gradient concentrations $2,4,6,8$, and $10 \mu \mathrm{g} \mathrm{l}^{-1}$ were injected into the sampler using an injection needle. The relevant data, peak time and peak area were then recorded. For example, the peak times of peaks I and II are shown in Fig. 2a, while the peak areas of the standards for the gradient concentrations $2,4,6,8$, and $10 \mathrm{\mu g} \mathrm{l}^{-1}$ were calculated to make Fig. 3a. The regression equation of the trans-phytoene is $y_{1}=5.488 x+0.2686, R^{2}=$ $0.9996>0.735$, which has a significant correlation with the concentration of the standard; the regression equation of the cis-phytoene is $y_{2}=1.8124 x-$ $0.2384, \mathrm{R}^{2}=0.975>0.735$, which has a significant correlation with the concentration of the standard. Referring to the peak time in Fig. 2b, the peak area of the standard of gradient concentrations of $2,4,6,8$, and $10 \mathrm{\mu g} \mathrm{l}^{-1}$ were calculated to make Fig. 3b. The regression equation of the astaxanthin is $y=$ $4.5161 x+0.6189, \mathrm{R}^{2}=0.999>0.735$, which also has a significant correlation with the concentration of the standard.

\subsection{Determination of phytoene and astaxanthin in $H$. pluvialis by HPLC}

The samples consisted of carotenoids obtained from $H$. pluvialis following induction by NaAc and high light. The phytoene and astaxanthin in the samples were determined based on the retention time and peak shape of the standard sample. The peak at 12.926 min corresponded to trans-phytoene, and the peak at $13.541 \mathrm{~min}$ to cis-phytoene, and the peak at $9.572 \mathrm{~min}$ to astaxanthin (Fig. 4).

\subsection{Effect of NaAc concentration on phytoene accumulation in $H$. pluvialis}

Phytoene accumulation differed when different concentrations of NaAc were added to the culture medium (Fig. 5). As the NaAc concentration increased during the early stage (4-8 d), the accumulation of phytoene gradually increased; in contrast, during the later stage (12-16 d), trends in accumulation began to diverge. Phytoene accumulation in the $3 \mathrm{~g} \mathrm{l}^{-1} \mathrm{NaAc}$ culture continued to increase and was significantly lower than that in the other NaAc groups during the early stage $(\mathrm{p}<0.05)$; however, phytoene accumulation was higher in the $3 \mathrm{~g} \mathrm{l}^{-1} \mathrm{NaAc}$ group compared with that in the $4-5 \mathrm{~g} \mathrm{l}^{-1} \mathrm{NaAc}$ groups on the $16^{\text {th }}$ day $(\mathrm{p}<0.05)$. The accumulation of phytoene in the $5 \mathrm{~g} \mathrm{l}^{-1}$ NaAc group rapidly reached its maximum during the early stage $(8 \mathrm{~d})$, which was higher than that in the 3 and $4 \mathrm{~g} \mathrm{l}^{-1} \mathrm{NaAc}$ groups, but began to decrease in the later stage, with the lowest content of phytoene occurring on the $12^{\text {th }}-16^{\text {th }}$ day. The $6 \mathrm{~g} \mathrm{l}^{-1} \mathrm{NaAc}$ group showed the most significant increase in phy-
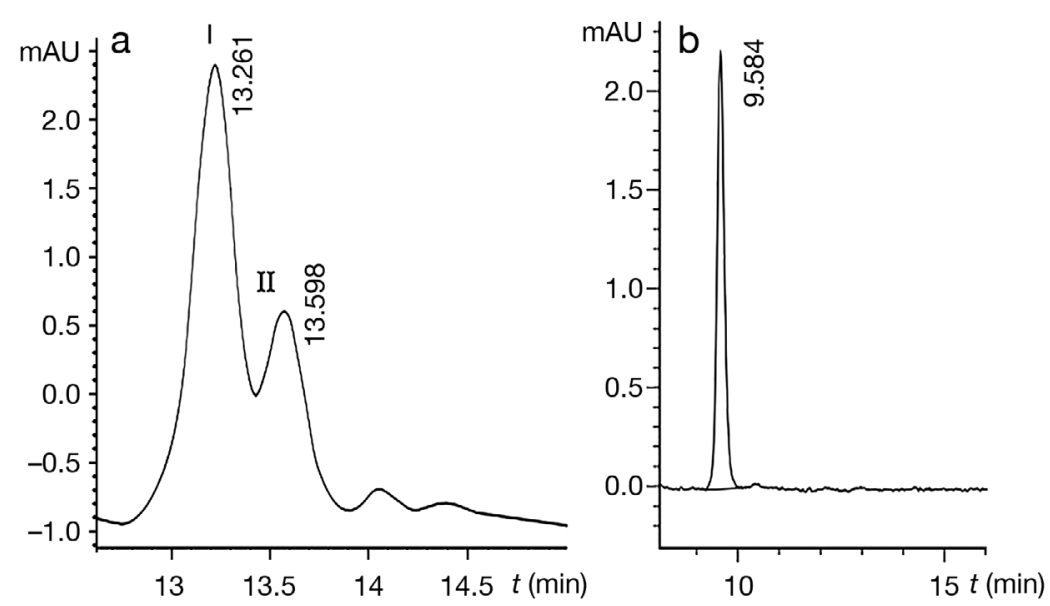

Fig. 2. Standard chromatogram using HPLC of (a) phytoene (I: trans-phytoene; II: cis-phytoene) and (b) astaxanthin 

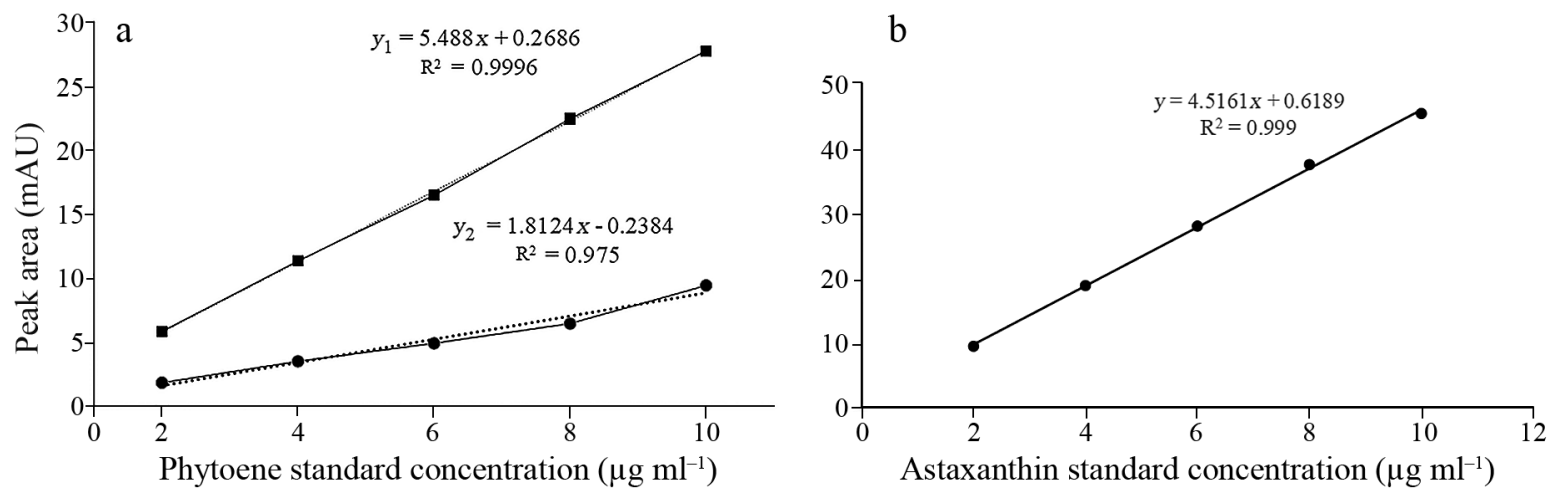

Fig. 3. (a) Analytical HPLC peak I and II area and concentration diagrams of phytoene reference substance. $y_{1}$ : trans-phytoene; $y_{2}$ : cis-phytoene. Regression curves taken with phytoene standard concentrations of 2, 4, 6, 8, and $10 \mu \mathrm{g} \mathrm{ml} \mathrm{m}^{-1}$. (b) Analytical HPLC area and concentration diagrams of astaxanthin reference substance. Regression curve taken with astaxanthin standard concentrations of $2,4,6,8$, and $10 \mu \mathrm{g} \mathrm{ml}^{-1}$

toene compared with the other 4 groups $(\mathrm{p}<0.05)$. In contrast, the peak of phytoene was too low to be integrated during the $16 \mathrm{~d}$ of induction for the group without NaAc.

\subsection{Effect of NaAc concentration on astaxanthin accumulation in $H$. pluvialis}

The accumulation of astaxanthin at different concentrations of NaAc reached its maximum on the $12^{\text {th }}$ day (Fig. 6). During the middle phase of induction, astaxanthin accumulation increased stably as NaAc concentration increased $(\mathrm{p}<0.05)$. At an NaAc concentration of $6 \mathrm{~g} \mathrm{l}^{-1}$, the concentration of astaxanthin reached a maximum.

\subsection{Relationship between astaxanthin and phytoene accumulation in $H$. pluvialis}

To ascertain the relationship between the accumulation of phytoene and astaxanthin, the concentrations of the 2 substances were analyzed together. The accumulation of phytoene and astaxanthin both increased gradually as the concentration of $\mathrm{NaAc}$ increased during the early stage $\left(4-8\right.$ d) (Figs. $5 \& 6$ ). On the $8^{\text {th }}$ day, there was a noticeable positive correlation between them. Thus, we selected the accumulation of astaxanthin and phytoene detected on the $8^{\text {th }}$ day to study the relationship at differ- ent concentrations of NaAc (Fig. 7a). Astaxanthin and phytoene both reached their highest levels when the concentration of NaAc was $6 \mathrm{~g} \mathrm{l}^{-1}$ (p < $0.05)$. Thus, we speculated that $6 \mathrm{~g} \mathrm{l}^{-1}$ was the optimal concentration for induction. The relationship between astaxanthin and phytoene under different induction times at an NaAc concentration of $6 \mathrm{~g} \mathrm{l}^{-1}$ is shown in Fig. 7b. The astaxanthin and phytoene content increased continuously with induction time from the $4^{\text {th }}$ day to the $12^{\text {th }}$ day. During the late induction period $\left(12^{\text {th }}-16^{\text {th }}\right.$ day $)$, the contents of astaxanthin and phytoene decreased. Astaxanthin and phytoene both reached their highest levels when the induction period was $12 \mathrm{~d}(\mathrm{p}<0.05)$. Thus, a period of $12 \mathrm{~d}$ was considered to be the optimal time for inducing phytoene and astaxanthin production.

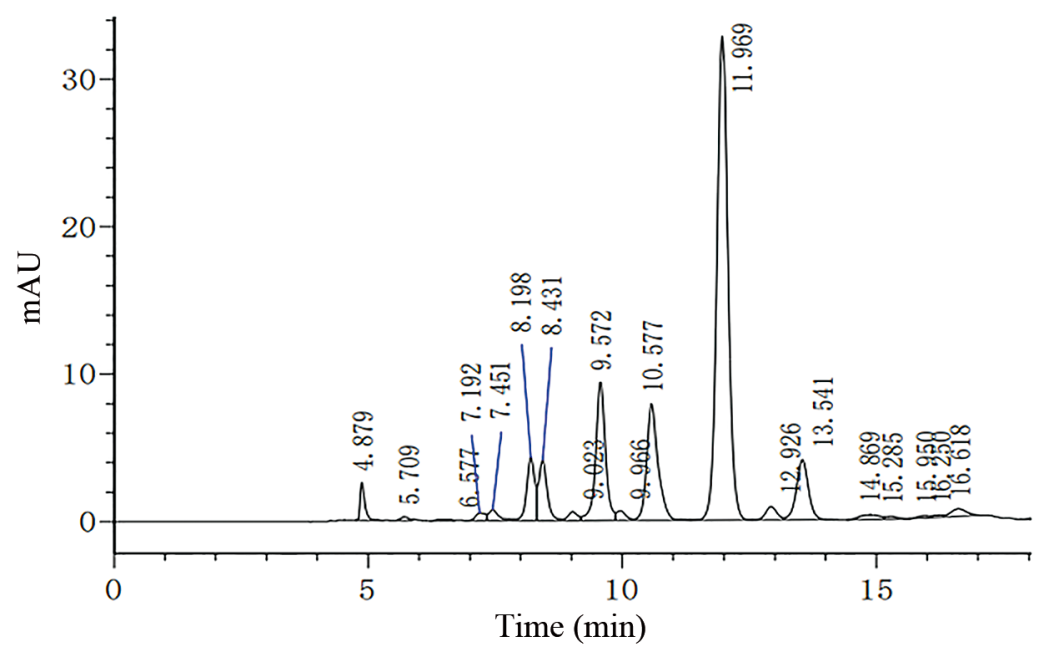

Fig. 4. Carotenoid profiles of Haematococcus pluvialis after induction, with different peak times 


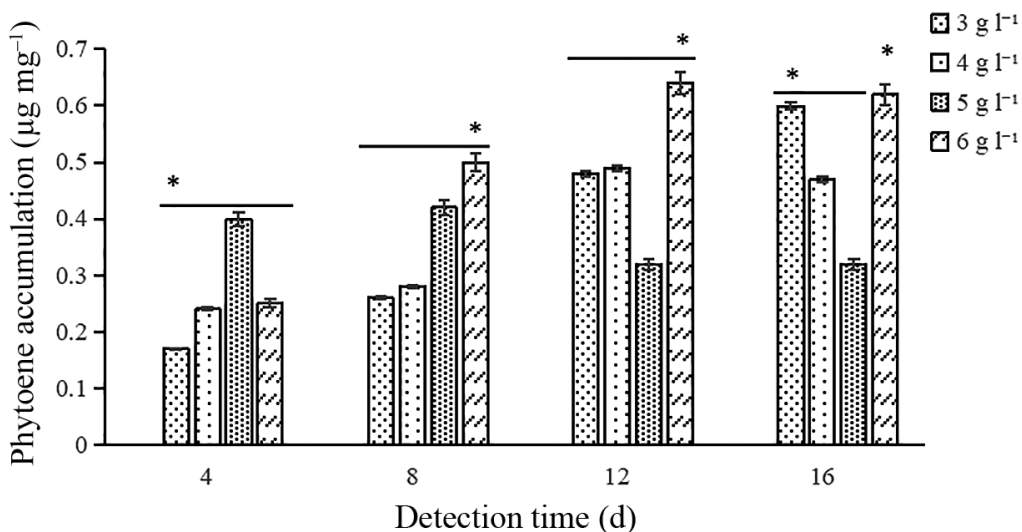

Fig. 5. Effect of sodium acetate concentration on phytoene accumulation in Haematococcus pluvialis. All data show mean \pm SD. Three independent experiments conducted $(n=3)$. ${ }^{*} \mathrm{p}<0.05$

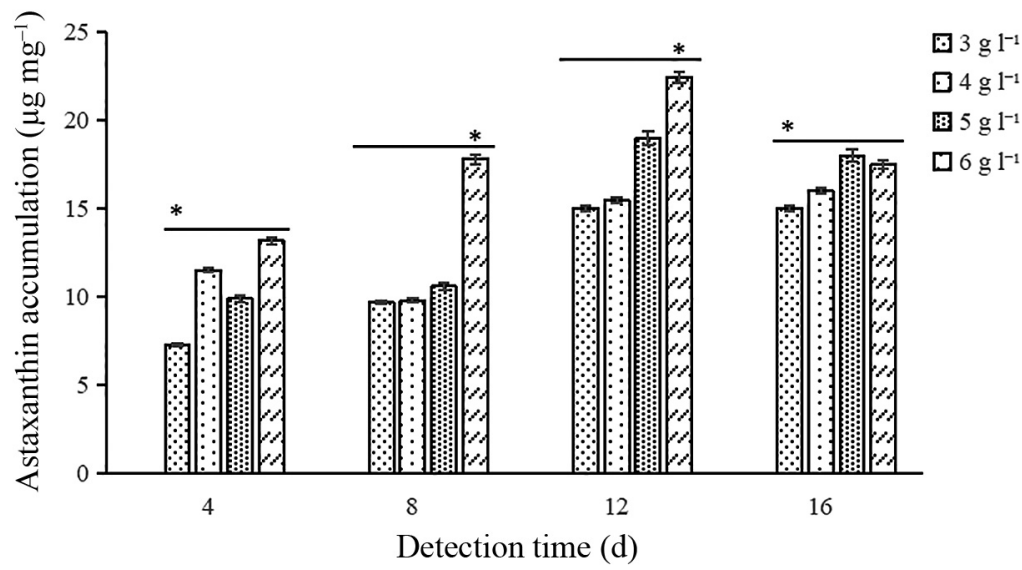

Fig. 6. Effect of sodium acetate concentration on astaxanthin accumulation in Haematococcus pluvialis. All data show mean \pm SD. Three independent experiments conducted $(n=3) .{ }^{*} p<0.05$

\subsection{Transcriptional-level analysis of carotenogenic genes}

The transcriptional levels of genes associated with general carotenogenesis and specific astaxanthin biosynthesis were quantified by qRT-PCR and compared with the transcription of these same genes in green motile cells (Fig. 8). These genes included $c r t w, c r t z, p s y, p d s$, and $1 c y B$. The transcriptional levels of $c r t w$ and $c r t z$ were both up-regulated since the first day of induction $(p<0.05)$. The transcripts of $c r t w$ of the 5 and $6 \mathrm{~g} \mathrm{l}^{-1} \mathrm{NaAc}$ groups reached their highest levels on the $9^{\text {th }}$ day $(p<0.05)$. The groups at the other $3 \mathrm{NaAc}$ concentrations increased until the $12^{\text {th }}$ day. However, the $\mathrm{crtz}$ transcripts of 0 and $3 \mathrm{~g} \mathrm{l}^{-1}$ reached their highest levels on the $3^{\text {rd }}$ day after exposure to the inductive conditions, and then reversed. After the $3^{\text {rd }}$ day, all of the groups maintained a sus- tained increase until the $12^{\text {th }}$ day, except for the transcripts crtz of the $5 \mathrm{~g} \mathrm{l}^{-1} \mathrm{NaAc}$ group, which reached its highest level on the $9^{\text {th }}$ day $(p<0.05)$. The transcriptional level of psy was up-regulated on the first day of induction, and reduced immediately on the $2^{\text {nd }}$ day $(\mathrm{p}<0.05)$. The psy transcripts of the 0,3 , and $4 \mathrm{gl}^{-1}$ groups began to increase from the $3^{\text {rd }}$ to the $12^{\text {th }}$ day, and reached their highest level on the $12^{\text {th }}$ day $(\mathrm{p}<0.05)$. The $p s y$ transcripts of the 5 and $6 \mathrm{~g} \mathrm{l}^{-1} \mathrm{NaAc}$ groups reached their highest levels on the $9^{\text {th }}$ day. The transcriptional levels of $p d s$ and $1 c y B$ showed a decreasing trend during the first $2 \mathrm{~d}(\mathrm{p}<0.05)$. They then began to increase starting on the $3^{\text {rd }}$ day of induction, with the transcripts of the 4 and $6 \mathrm{~g} \mathrm{l}^{-1} \mathrm{NaAc}$ groups reaching their highest levels on the $12^{\text {th }}$ day $(p<0.05)$. Overall, all 5 genes were highly transcribed under NaAc concentrations of 4 and $6 \mathrm{~g} \mathrm{l}^{-1}$ on the $12^{\text {th }}$ day. The optimal induction concentration of $\mathrm{NaAc}$ and induction time for maximizing the production of astaxanthin and phytoene in H. pluvialis was $6 \mathrm{~g} \mathrm{l}^{-1}$ and $12 \mathrm{~d}$, respectively.

\section{DISCUSSION}

Haematococcus pluvialis has been shown to accumulate large amounts of carotenoids when exposed to stress, such as nitrogen and phosphate limitation, salt stress, and high light intensities (Johnson \& Schroeder 1996). Astaxanthin content or cell density of $H$. pluvialis under nitrogen starvations was significantly lower than that under conditions with sufficient nitrogen (Jinxun et al. 2016). Although astaxanthin accumulation is usually conducted by high light condition (Scibilia et al. 2015), excess light energy may accelerate the generation of reactive oxygen species (ROS), resulting in photoinhibition (Zhang et al. 2011). Conditions contributing to astaxanthin accumulation in $H$. pluvialis include high light intensity $\left(175 \mu \mathrm{mol}\right.$ photons $\left.\mathrm{m}^{-2} \mathrm{~s}^{-1}\right)$, nitrogen limitation, phosphate or sulfate starvation, and salt stress $(0.8 \% \mathrm{NaCl})$ (Boussiba et al. 1992). We selected a light intensity of $172 \mu \mathrm{mol}$ photons $\mathrm{m}^{-2} \mathrm{~s}^{-1}$ without nitrogen to induce red cysts in the present study. Previous work has shown that when NaAc acts as the carbon source, 

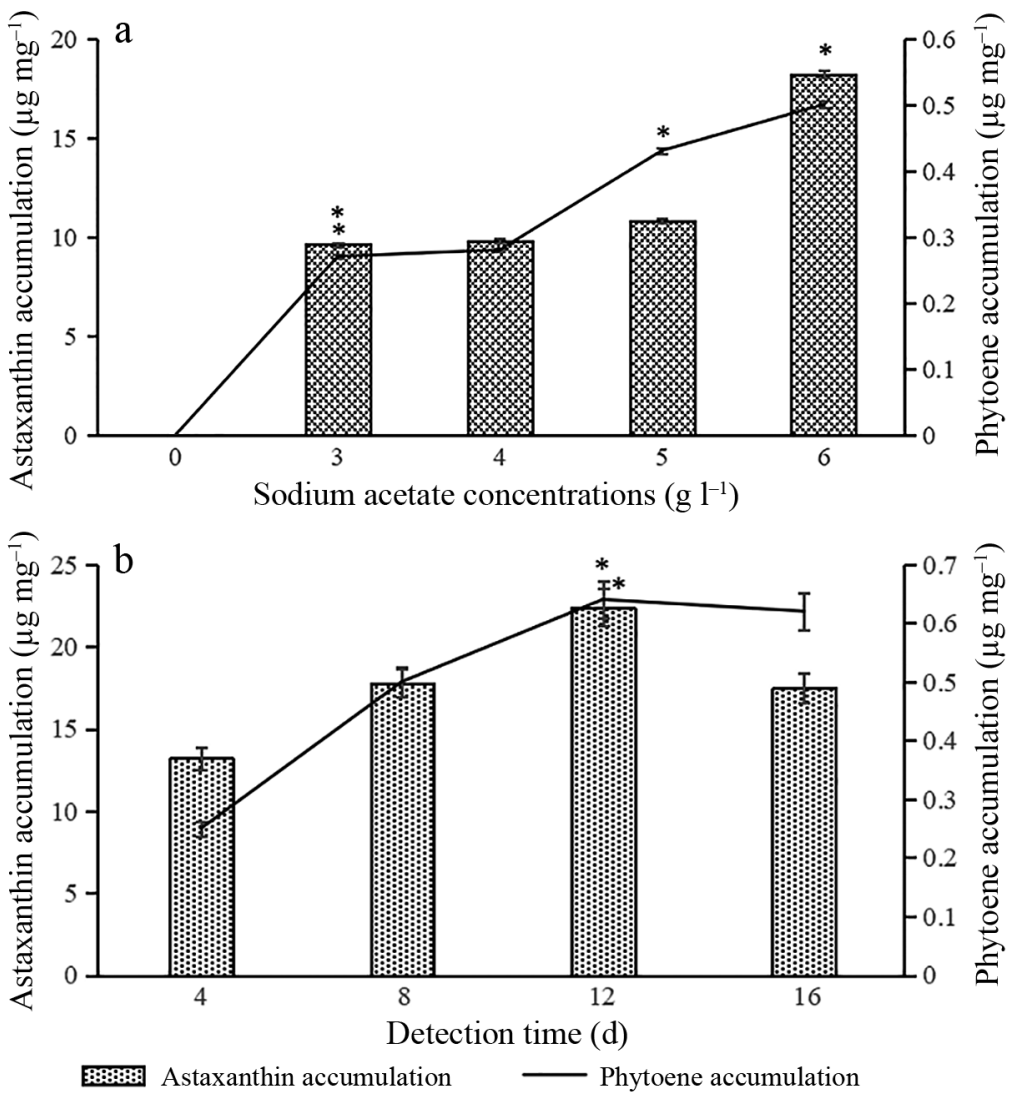

Fig. 7. Relationship between astaxanthin and phytoene accumulation in Haematococcus pluvialis: (a) in different sodium acetate concentrations, and (b) under different detection times. All data show mean \pm SD. Three independent experiments conducted $(n=3) .{ }^{*} \mathrm{p}<0.05$

astaxanthin accumulation in $H$. pluvialis is accelerated (Orosa et al. 2001). Exogenous NaAc enhances astaxanthin accumulation and photoprotection capacity in $H$. pluvialis at the non-motile stage (Zhang et al. 2018). In our study, phytoene and astaxanthin accumulated little in the group without NaAc, suggesting that NaAc plays an important role in carotenoid synthesis.

The accumulation of phytoene showed different trends in the early induction phase and in the later induction phase. During the initial stage of induction, the concentration of phytoene increased as the concentration of NaAc increased, indicating that phytoene, the upstream metabolite of carotenoids, was primarily synthesized during this period. Phytoene is consumed as a precursor of astaxanthin in the later induction period; thus, the concentration of phytoene showed different trends under different concentrations of NaAc. High concentrations of $\mathrm{NaAc}$ in $H$. pluvialis can increase the accumulation of both phytoene and astaxanthin. The optimal induction concentration of $\mathrm{NaAc}$ was inferred to be $6 \mathrm{~g} \mathrm{l}^{-1}$ and the induction time $12 \mathrm{~d}$.

Related studies have found that high concentrations of NaAc are not conducive to cell growth. Although high salinity can accelerate the formation of cysts in $H$. pluvialis, excessive salinity can promote cell death (Tao et al. 2015). In our study, medium concentrations $\left(3-5 \mathrm{~g} \mathrm{l}^{-1}\right)$ of NaAc during the early induction stage increased the weight of the algal cells, while high concentrations (e.g. $6 \mathrm{~g} \mathrm{l}^{-1}$ ) of NaAc reduced the dry weight of algal cells during the initial induction stage, which promoted cell death. However, over medium timeframes $\left(8^{\text {th }}\right.$ day $)$, a high concentration (e.g. $6 \mathrm{~g} \mathrm{l}^{-1}$ ) of NaAc promoted increases in dry weight. The explanation for this pattern might be that the high concentration of NaAc induced algal cells to produce thicker cyst walls as a self-protective mechanism, which might have increased cell mass rather than cell growth (He et al. 2018). The effect of $\mathrm{NaAc}$ on astaxanthin accumulation is always integrated with increased biomass production (Göksan et al. 2010). Astaxanthin is known to accumulate in the thick-walled cyst cells of $H$. pluvialis (Sarada et al. 2006). Thus, we infer that the optimal induction concentration of NaAc is $6 \mathrm{~g}$ $\mathrm{l}^{-1}$, and the induction time is $12 \mathrm{~d}$.

Carotenogenic genes, such as bkt and chy, along with $p s y, p d s$, and $l c y$, were all up-regulated under stresses, such as high light intensity, salinity, acetate addition, and nutrient depletion. These carotenogenic gene transcripts have even been detected in 3 mo old cysts (Vidhyavathi et al. 2007, 2008). When green cells were transformed to red cysts under stress, total carotenoids in the cells increased and ketocarotenoids were preferentially formed (Huang et al. 2006). This pattern was coupled with the upregulation of the genes for $\beta$-carotene ketolase and hydroxylase (Grünewald et al. 2000, Steinbrenner \& Linden 2001). The bkt and crtz genes are not expressed in the absence of stress (Lemoine \& Schoefs 2010). In this study, crtw and crtz were continually up-regulated under the stress of high light and NaAc, probably because they are 2 key enzymes involved in astaxanthin synthesis. PSY plays an important role in the first major reaction of the carotenoid biosynthetic pathway (Cárdenas et 


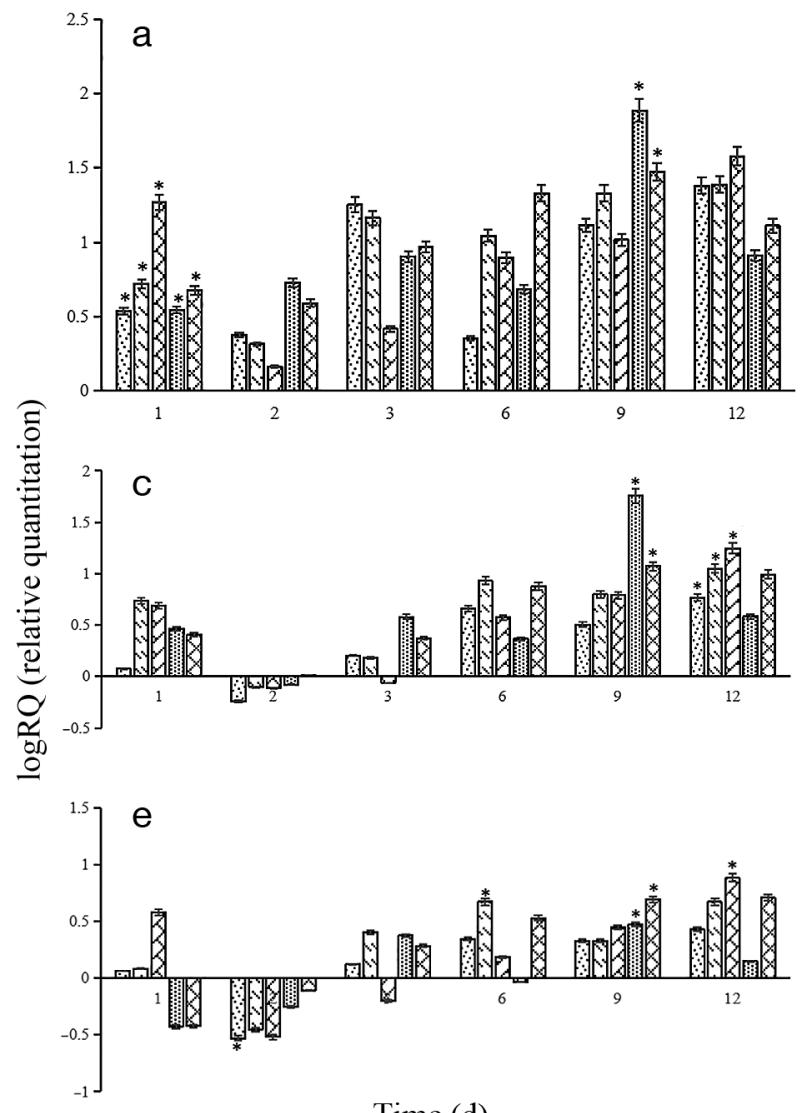

Time (d)

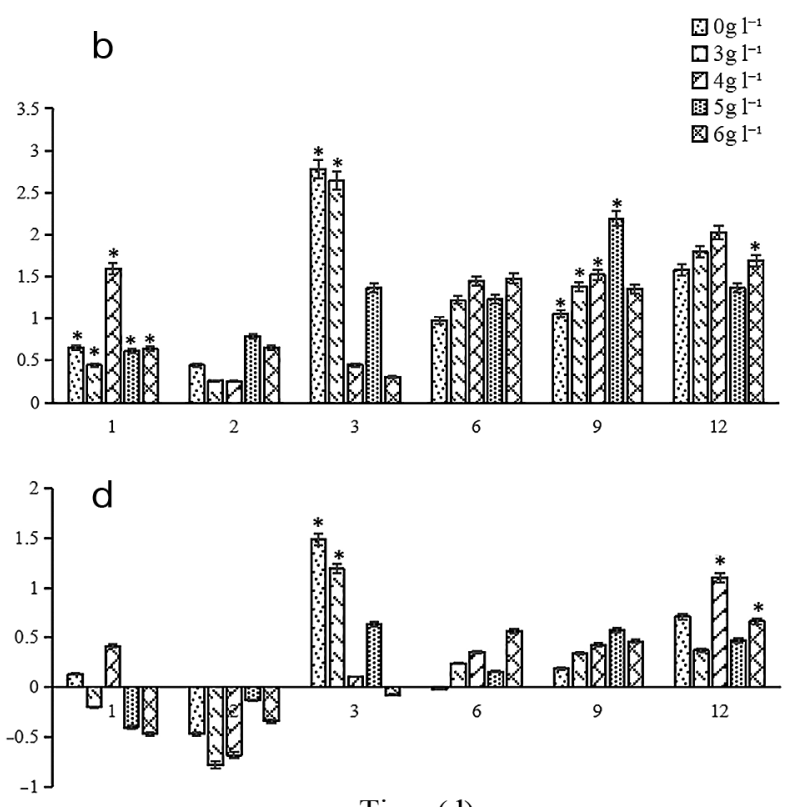

Time (d) al. 2012). The expression of psy under different environmental stresses showed that the expression of psy could be detected after $4 \mathrm{~h}$ of induction and reached its highest level after 1-2 d under the simultaneous application of NaAc, ferrous sulfate, and high light intensity (Jia et al. 2014). psy is overexpressed in lettuce cells under salt stress, suggesting that changes in psy expression depend on the relative degrees of external stress. We found that psy was up-regulated on the $1^{\text {st }}$ day of induction. Although its transcriptional level was lower the $2^{\text {nd }}$ day, on the $3^{\text {rd }}$ day, the transcription level of psy began to rise again. The transcriptional level of psy increased as the concentration of NaAc increased, which is consistent with patterns in the accumulation of phytoene and astaxanthin. Previous studies have primarily focused on the transcriptional level of $p d s$ and found that mRNA levels of $p d s$ are highest when astaxanthin accumulates (Giuliano et al. 1993, Steinbrenner \& Linden 2001). Trends in the transcription of $p d s$ were below their initial value during the first $2 \mathrm{~d}$, at which point it began to be up-regulated. Grünewald et al. (2000) have demonstrated that $p d s$ is up-regulated at the mRNA level
Fig. 8. Transcripts of 5 carotenogenic genes of Haematococcus pluvialis: (a) $c r t w$, (b) $c r t z$, (c) psy, (d) pds, and (e) $l_{c y B}$, under different concentrations of sodium acetate. All data show mean $\pm \mathrm{SD}$. Three independent experiments conducted (n $=3) .{ }^{*} \mathrm{p}<0.05$

during accumulation of secondary carotenoids in $H$. pluvialis. The down-regulation of psy and pds might be caused by environmental changes.

Changes in $l_{c y} B$ under induction conditions are inconsistent with changes in psy and pds. Studies have shown that a certain range of salt concentrations can up- or down-regulate the expression of $l_{C y} B$, and the expression of $l_{c y B}$ in leaves of different processed tomato varieties increases as the concentration of salt increases (Zhang et al. 2014). These differences might stem from the fact that the genotypes of different varieties vary in salt tolerance (Liang et al. 2009). For example, RNAi technology has been used to inhibit the expression of $1 c y B$ and lycopene content of transgenic tomatoes has been found to be significantly increased. In addition, under intense light and nitrogen-deficiency conditions, there was no significant increase in lcyB expression in wildtype $H$. pluvialis when cells changed from green to red (Wei \& Madeline 2002). In our study, the expression of $1 c y B$, like other carotenogenic genes, increased as the concentration of $\mathrm{NaAc}$ increased and its expression appeared to exhibit certain synergy with other carotenogenic genes. 
The accumulation of phytoene was consistent with the accumulation of astaxanthin, and $6 \mathrm{~g} \mathrm{l}^{-1} \mathrm{NaAc}$ was the most favorable concentration for the accumulation of carotenoids. During the process of induction, the transcriptional levels of all 5 of these genes nearly stopped increasing or decreasing on the $12^{\text {th }}$ day. Thus, long-term induction could not increase the expression level of genes related to astaxanthin biosynthesis. The content of astaxanthin also showed its highest concentration on the $12^{\text {th }}$ day. Thus, harvesting of $H$. pluvialis should be conducted on the $12^{\text {th }}$ day after induction. This study enhances our understanding of the relationship between carotenoids and the expression of carotenoid-related genes. Moreover, this study establishes the optimal conditions for inducing the accumulation of carotenoids.

Acknowledgements. This research was supported by the National Natural Science Foundation of China (Grant No. 31872555) and China Agriculture Research System (CARS50). The authors declare that they have no conflict of interest.

\section{LITERATURE CITED}

Boussiba S (2000) Carotenogenesis in the green alga Haematococcus pluvialis: cellular physiology and stress response. Physiol Plant 108:111-117

Boussiba S, Fan L, Vonshak A (1992) Enhancement and determination of astaxanthin accumulation in green alga Haematococcus pluvialis. Methods Enzymol 213: 386-391

Cárdenas PD, Gajardo HA, Huebert T, Parkin IA, IniguezLuy FL, Federico ML (2012) Retention of triplicated phytoene synthase (PSY) genes in Brassica napus L. and its diploid progenitors during the evolution of the Brassiceae. Theor Appl Genet 124:1215-1228

Dere S, Gunes T, Sivaci R (1998) Spectrophotometric determination of chlorophyll-A, B and total carotenoid contents of some algae species using different solvents. Turk J Bot 22:13-17

Fábregas J, Domínguez A, Regueiro M, Maseda A, Otero A (2000) Optimization of culture medium for the continuous cultivation of the microalga Haematococcus pluvialis. Appl Microbiol Biotechnol 53:530-535

Fraser PD, Shimada H, Misawa N (1998) Enzymic confirmation of reactions involved in routes to astaxanthin formation, elucidated using a direct substrate in vitro assay. Eur J Biochem 252:229-236

Fujii K (2015) Isolation of astaxanthin-producing microalgae and potential biotechnological applications. Curr Biotechnol 4:492

Gao Z, Meng C, Zhang X, Xu D and others (2012) Induction of salicylic acid (SA) on transcriptional expression of eight carotenoid genes and astaxanthin accumulation in Haematococcus pluvialis. Enzyme Microb Technol 51: 225-230

Giuliano G, Bartley GE, Scolnik PA (1993) Regulation of carotenoid biosynthesis during tomato development. Plant Cell 5:379-387
Göksan T, Ak İ, Şevket G (2010) An alternative approach to the traditional mixotrophic cultures of Haematococcus pluvialis Flotow (Chlorophyceae). J Microbiol Biotechnol 20:1276-1282

* Grünewald K, Eckert M, Hirschberg J, Hagen C (2000) Phytoene desaturase is localized exclusively in the chloroplast and up-regulated at the mRNA level during accumulation of secondary carotenoids in Haematococcus pluvialis (Volvocales, Chlorophyceae). Plant Physiol 122: 1261-1268

Grünewald K, Hirschberg J, Hagen C (2001) Ketocarotenoid biosynthesis outside of plastids in the unicellular green alga Haematococcus pluvialis. J Biol Chem 276: 6023-6029

* Harker M, Young A (1995) Inhibition of astaxanthin synthesis in the green alga, Haematococcus pluvialis. Eur J Phycol 30:179-187

He B, Hou L, Dong M, Shi J and others (2018) Transcriptome analysis in Haematococcus pluvialis: astaxanthin induction by high light with acetate and $\mathrm{Fe}^{2+}$. Int J Mol Sci 19:175

*Huang JC, Chen F, Sandmann G (2006) Stress-related differential expression of multiple beta-carotene ketolase genes in the unicellular green alga Haematococcus pluvialis. J Biotechnol 122:176-185

Jackson H, Braun CL, Ernst H (2008) The chemistry of novel xanthophyll carotenoids. Am J Cardiol 101(10 Suppl): S50-S57

Jia D, Fan L, Shen J, Liu C, Yuan Y, Qin S, Cui C (2014) Biological synthesis of astaxanthin in apple callus by genetic transformation of BKT and CRTR-B from Haematococcus pluvialis. Acta Hortic 1048:143-150

Jinxun LI, Siyuan XU, Jin W (2016) Effects of nitrogen deficiency on Haematococcus pluvialis PhotosystemII photochemical changes and changes of astaxanthin. J Hubei Univ Technol 2:111-115

*Johnson EA, Schroeder WA (1996) Microbial carotenoids. Adv Biochem Eng Biotechnol 53:119-178

KLemoine Y, Schoefs B (2010) Secondary ketocarotenoid astaxanthin biosynthesis in algae: a multifunctional response to stress. Photosynth Res 106:155-177

Liang CW, Tan CP, Zhong-Liang SU, Wei W, Qin S (2009) Cloning and functional characterization of phytoene desaturase gene (pds) promoter from Haematococcus pluvlialis. Mar Sci Bull 6:46-50

KLinden H (1999) Carotenoid hydroxylase from Haematococcus pluvialis: cDNA sequence, regulation and functional complementation. Biochim Biophys Acta 1446:203-212

* Liu J, Li Q, Qian L, He M, Han C (2014) Screening of unicellular microalgae for biofuels and bioactive products and development of a pilot platform. Algol Stud 145-146: 99-117

Livak KJ, Schmittgen TD (2001) Analysis of relative gene expression data using real-time quantitative PCR and the $2^{-\triangle \triangle C_{T}}$ method. Methods 25:402-408

* Lotan T, Hirschberg J (1995) Cloning and expression in Escherichia coli of the gene encoding $\beta$-C-4-oxygenase, that converts $\beta$-carotene to the ketocarotenoid canthaxanthin in Haematococcus pluvialis. FEBS Lett 364:125-128

Orosa M, Franqueira D, Cid A, Abalde J (2001) Carotenoid accumulation in Haematococcus pluvialis in mixotrophic growth. Biotechnol Lett 23:373-378

* Poojary MM, Barba FJ, Aliakbarian B, Donsì F, Pataro G, Dias DA, Juliano P (2016) Innovative alternative technologies to extract carotenoids from microalgae and seaweeds. Mar Drugs 14:214 
Raman V, Ravi S (2011) Effect of salicylic acid and methyl jasmonate on antioxidant systems of Haematococcus pluvialis. Acta Physiol Plant 33:1043-1049

Sarada R, Vidhyavathi R, Usha D, Ravishankar GA (2006) An efficient method for extraction of astaxanthin from green alga Haematococcus pluvialis. J Agric Food Chem 54:7585-7588

Scibilia L, Girolomoni L, Berteotti S, Alboresi A, Ballottari M (2015) Photosynthetic response to nitrogen starvation and high light in Haematococcus pluvialis. Algal Res 12: 170-181

Steinbrenner J, Linden H (2001) Regulation of two carotenoid biosynthesis genes coding for phytoene synthase and carotenoid hydroxylase during stress-induced astaxanthin formation in the green alga Haematococcus pluvialis. Plant Physiol 125:810-817

Tao YY, Wang QH, Gong QL (2015) The study progress of Haematococcus pluvialis growth and astaxanthin accumulation conditions. Hebei Fisheries 7:49-52

Tripathi U, Sarada R, Rao SR, Ravishankar G (1999) Production of astaxanthin in Haematococcus pluvialis cultured in various media. Bioresour Technol 68:197-199

Vidhyavathi R, Venkatachalam L, Kamath BS, Sarada R, Ravishankar GA (2007) Differential expression of carotenogenic genes and associated changes in pigment pro-

Editorial responsibility: Wen-Xiong Wang, Kowloon, Hong Kong, SAR file during regeneration of Haematococcus pluvialis cysts. Appl Microbiol Biotechnol 75:879-887

*Vidhyavathi R, Venkatachalam L, Sarada R, Ravishankar GA (2008) Regulation of carotenoid biosynthetic genes expression and carotenoid accumulation in the green alga Haematococcus pluvialis under nutrient stress conditions. J Exp Bot 59:1409-1418

Wei D, Madeline C (2002) New advances on regulatory mechanisms of astaxanthin accumulation in Haematococcus pluvialis under inducing conditions. Chinese J Mar Drugs 2:60-64

Zhang LT, Zhang ZS, Gao HY, Xue ZC, Yang C, Meng XL, Meng QW (2011) Mitochondrial alternative oxidase pathway protects plants against photoinhibition by alleviating inhibition of the repair of photodamaged PSII through preventing formation of reactive oxygen species in Rumex K-1 leaves. Physiol Plant 143:396-407

Zhang F, Zhang B, Tian LP, Xue L, Li HL, Zeng YH (2014) Effect of salt stress on expression of lycopene cyclase gene in processing tomato leaves. North Horticult 4: 82-85

Khang C, Zhang L, Liu J (2018) Exogenous sodium acetate enhances astaxanthin accumulation and photoprotection in Haematococcus pluvialis at the non-motile stage. J Appl Phycol 31:1001-1008

Submitted: February 11, 2020; Accepted: July 28, 2020

Proofs received from author(s): November 15, 2020 